\title{
Classification of Pecorino cheeses produced in Italy according to their ripening time and manufacturing technique using Fourier transform infrared spectroscopy
}

\author{
M. J. Lerma-García, ${ }^{*}$ A. Gori, $\dagger$ L. Cerretani, $\dagger^{1}$ E. F. Simó-Alfonso, ${ }^{*}$ and M. F. Caboni† \\ *Departamento de Química Analítica, Universidad de Valencia, C. Doctor Moliner 50, E-46100 Burjassot, Valencia, Spain \\ †Dipartimento di Scienze degli Alimenti, Università di Bologna, P. zza Goidanich 60, I-47521 Cesena (FC), Italy
}

\begin{abstract}
Fourier-transform infrared spectroscopy, followed by linear discriminant analysis of the spectral data, was used to classify Italian Pecorino cheeses according to their ripening time and manufacturing technique. The Fourier transform infrared spectra of the cheeses were divided into 18 regions and the normalized absorbance peak areas within these regions were used as predictors. Linear discriminant analysis models were constructed to classify Pecorino cheeses according to different ripening stages (hard and semi-hard) or according to their manufacturing technique (fossa and nonfossa cheeses). An excellent resolution was achieved according to both ripening time and manufacturing technique. Also, a final linear discriminant analysis model considering the 3 categories (hard nonfossa, hard fossa, and semi-hard nonfossa) was constructed. A good resolution among the 3 categories was obtained.
\end{abstract}

Key words: Fourier transform infrared spectroscopy, linear discriminant analysis, Pecorino cheese, ripening time

\section{INTRODUCTION}

Several traditional Italian dairy products are made from ewe's milk, particularly ewe's cheeses, which are the predominant food products made from ewe's milk. They are also known with the generic term "Pecorino," indicating all cheeses made only from raw or thermized ewe's milk and mainly produced in the middle and south of Italy according to ancient and unique manufacturing techniques. Some of them are known worldwide because they have the prestigious appellation of "Protected Denomination of Origin" (such as Pecorino Sardo, Pecorino Romano, Pecorino Toscano, Pecorino Siciliano, Fiore Sardo, Canestrato Pugliese, and Fossa cheese from Sogliano al Rubicone and Talamello); however, a large

Received February 23, 2010.

Accepted June 4, 2010.

${ }^{1}$ Corresponding author: lorenzo.cerretani@unibo.it number of Pecorino cheeses exist in Italy that have a geographical origin but do not have the Protected Denomination of Origin appellation. Regarding fossa cheese, a typical feature is seasoning in flask-shaped pits that are dug in the tufa soil of Sogliano al Rubicone (Emilia-Romagna region, Italy). These cheeses are ripened in the pits from 80 to $100 \mathrm{~d}$ only after a period of maturation in rooms, which is necessary to achieve a certain degree of consistency. The full ripening takes a minimum of 3 mo to a maximum of 8 mo.

Several factors affect the typicity of cheeses: the geographical area (the fodder/pasture consumed by the animals), the cheese processing, and the degree of ripening. Degree of ripening influences the final development of the sensory properties of the cheese through biochemical events (proteolysis, glycolysis, and lipolysis) that occur during this phase of the cheese processing (Fox et al., 1993; McSweeney and Sousa, 2000).

Several analytical methods are used to evaluate these processes (Luykx and van Ruth, 2008). The utility of these methods has been described in depth in cheese ripening evaluation (Gagnaire et al., 2001; Moatsou et al., 2002; Gorostiza et al., 2004; Poveda et al., 2004; Verdini et al., 2004), even though many cheesemakers still assess the ripening status by a limited number of measurements (e.g., $\mathrm{pH}$ and weight) or by visual and tactile examination. Current analytical methods, consisting of chemometric elaborations of physicochemical parameters and secondary proteolysis indices (Contarini et al., 2001; Poveda et al., 2004) or peptide and AA chromatograms (Fallico et al., 2004), are destructive, expensive, and time consuming; in addition, these methods require highly skilled operators. Therefore, there is increasing interest in noninvasive and nondestructive techniques that rapidly estimate the ripening time when required from an easy-to-use and low-cost method. Fourier transform infrared (FTIR) spectroscopy is a direct, reliable, and fast method (Karoui et al., 2004) that can be easily applied in fundamental research, in control laboratories, and on-line in the factories to analyze food products. An FTIR spectrometer obtains infrared spectra $\left(4,000\right.$ to $\left.700 \mathrm{~cm}^{-1}\right)$ by collecting an in- 
Table 1. Number of samples corresponding to the different geographical origins (city and region of Italy), ripening times, and manufacturing techniques of the Italian Pecorino cheeses employed in this study

\begin{tabular}{|c|c|c|c|}
\hline \multirow[b]{3}{*}{ Geographical origin } & \multicolumn{3}{|c|}{ Ripening time and manufacturing technique } \\
\hline & \multirow{2}{*}{$\begin{array}{c}\text { Semi-hard } \\
\text { nonfossa }\end{array}$} & \multicolumn{2}{|c|}{ Hard } \\
\hline & & Fossa & Nonfossa \\
\hline L'Aquila (Abruzzo) & 1 & - & 1 \\
\hline Potenza (Basilicata) & 1 & - & 1 \\
\hline Avellino (Campania) & 1 & - & - \\
\hline Forlì-Cesena (Emilia-Romagna) & - & 7 & 2 \\
\hline Rimini (Emilia-Romagna) & 2 & 1 & 1 \\
\hline Trieste (Friuli-Venezia-Giulia) & - & - & 1 \\
\hline Pesaro-Urbino (Marche) & 1 & 2 & 2 \\
\hline Nuoro (Sardegna) & 1 & - & 3 \\
\hline Oristano (Sardegna) & 1 & - & 1 \\
\hline Pisa (Toscana) & - & 1 & 2 \\
\hline
\end{tabular}

terferogram of a sample signal with an interferometer, which measures all of infrared frequencies simultaneously. It makes it possible to assign specific bands to specific chemical entities because bands are associated with vibrations of functional groups of the molecules (Coates, 2000). Fourier transform infrared spectroscopy has been used to investigate associated bands of proteins, fats, lactose, and lactic acid in dairy products, and recently they have been applied on ripened cheese to measure their composition (Rodriguez-Saona et al., 2006), sensory and texture parameters (Blazquez et al., 2006), geographic origin (Karoui et al., 2005), and ripening time (Chen et al., 1998; Mazerolles et al., 2001; Downey et al., 2005; Martin-del-Campo et al., 2007). Because no studies have yet been carried out on ewe's milk cheese, the purpose of this investigation was to classify different Italian Pecorino cheeses according to their ripening time and manufacturing technique by attenuated total reflectance (ATR) FTIR spectroscopy, dividing the spectra into 18 regions (peaks and shoulders observed) and using linear discriminant analysis (LDA) of the spectral data.

\section{MATERIALS AND METHODS}

\section{Pecorino Cheeses and Sample Treatment}

The study was carried out in 33 Pecorino cheeses produced in 8 different Italian regions (Table 1). Samples were classified as follows: semi-hard nonfossa (ripening times between 2 and $6 \mathrm{mo}$ ) and hard fossa and nonfossa (ripening times higher than $6 \mathrm{mo}$ ), with fossa and nonfossa being the different manufacturing techniques employed to obtain the cheeses. All the samples were kindly donated by the organizers of the sixth national concourse "Ovillus Aureus, the Gold Pecorino Cheese" (November 28th, 2008, Fano, Italy) reserved to the typical Italian Pecorino cheeses and fossa Pecorino cheeses.
The ripening time and manufacturing technique of all the samples were guaranteed by the suppliers.

For FTIR analysis, 3 portions of $15 \mathrm{~g}$ of each Pecorino cheese were randomly taken, triturated with mortar and pestle, and mixed. Then, $1 \mathrm{~g}$ from each portion was removed and measured.

\section{FTIR Spectra}

All spectra were acquired using a Tensor 27 FTIR spectrometer system (Bruker Optics, Milan, Italy), fitted with a Rocksolid interferometer and a DigiTect detector system coupled to an ATR accessory. The ATR was a Pike MIRacle accessory (Pike Technologies, Madison, WI) for the analysis of solids among other materials. This ATR was equipped with a ZnSe reflection crystal and a MIRacle high-pressure clamp (all equipment from Bruker Optics). All analyses were carried out at room temperature. Spectra were acquired (32 scans/sample or background) in the range of 4,000 to $700 \mathrm{~cm}^{-1}$ at a resolution of $4 \mathrm{~cm}^{-1}$, using OPUS r. 6.0 software (Bruker Optics).

Each Pecorino cheese was deposited in the ATR surface and pressed with the pressure clamp to obtain a thin cheese layer. Then, the absorbance spectrum was collected against a background obtained with a dry and empty ATR cell. Three spectra were recorded for each portion. Before acquiring each spectrum, the ATR crystal was cleaned with a cellulose tissue soaked in $n$-hexane and then rinsed with acetone.

\section{Data Treatment and Statistical Analysis}

Fourier transform infrared spectra were divided into the 18 wavelength regions described in Table 2. Each selected spectral region corresponds to a peak or a shoulder, representing structural or functional group information. For each region, the peak/shoulder area 
Table 2. Fourier transform infrared spectral regions selected as predictor variables for statistical data treatment

\begin{tabular}{|c|c|c|c|c|}
\hline Identification no. & Range, $\mathrm{cm}^{-1}$ & $\begin{array}{l}\text { Functional } \\
\text { group }\end{array}$ & $\begin{array}{l}\text { Nominal } \\
\text { frequency }\end{array}$ & $\begin{array}{l}\text { Mode of } \\
\text { vibration }\end{array}$ \\
\hline 1 & $3,703-3,323$ & $\begin{array}{l}-\mathrm{N}-\mathrm{H} \\
-\mathrm{O}-\mathrm{H}\end{array}$ & 3,350 & Stretching \\
\hline 3 & $3,012-2,948$ & $\begin{array}{l}=\mathrm{C}-\mathrm{H}(\mathrm{cis}) \\
-\mathrm{C}-\mathrm{H}\left(\mathrm{CH}_{3}\right)\end{array}$ & $\begin{array}{l}3,006 \\
2,953\end{array}$ & $\begin{array}{l}\text { Stretching } \\
\text { Stretching (asymmetrical) }\end{array}$ \\
\hline 7 & $1,721-1,594$ & $-\mathrm{C}=\mathrm{O}($ acid, amide $\mathrm{I})$ & 1,711 & Stretching \\
\hline 8 & $1,594-1,485$ & -N-H (amide II) & - & Bending \\
\hline 9 & $1,485-1,433$ & $\begin{array}{l}-\mathrm{C}-\mathrm{H}\left(\mathrm{CH}_{2}\right) \\
-\mathrm{C}-\mathrm{H}\left(\mathrm{CH}_{3}\right)\end{array}$ & $\begin{array}{l}1,465 \\
1,450\end{array}$ & $\begin{array}{l}\text { Bending (scissoring) } \\
\text { Bending (asymmetrical) }\end{array}$ \\
\hline 10 & $1,433-1,375$ & $\begin{array}{l}=\mathrm{C}-\mathrm{H}(\text { cis }) \\
-\mathrm{C}-\mathrm{H}\left(\mathrm{CH}_{3}\right)\end{array}$ & $\begin{array}{l}1,417 \\
1,377\end{array}$ & $\begin{array}{l}\text { Bending (rocking) } \\
\text { Bending (symmetrical) }\end{array}$ \\
\hline 15 & $1,211-1,139$ & $-\mathrm{CH}_{2-}^{-\mathrm{O}}$ & 1,163 & $\begin{array}{l}\text { Stretching } \\
\text { Bending }\end{array}$ \\
\hline 16 & $1,139-1,105$ & $-\mathrm{C}-\mathrm{O}$ & 1,118 & Stretching \\
\hline 17 & $1,105-1,018$ & $-\mathrm{C}-\mathrm{O}$ & $\begin{array}{l}1,097 \\
1,033\end{array}$ & Stretching \\
\hline 18 & $1,018-955$ & $-\mathrm{HC}=\mathrm{CH}-($ trans $)$ & 968 & Bending (out of plane) \\
\hline
\end{tabular}

${ }^{1}$ According to Silverstein et al. (1981), Chen et al. (1998), Rodriguez-Soana et al. (2006), and Lerma-García et al. (2010).

was measured. To reduce the variability associated with the total amount of sample used, and to minimize other sources of variance also affecting the intensity of all the peaks, normalized rather than absolute areas were used. Then, the area of each region was divided by each of the areas of the other 17 regions; in this way, and because any pair of areas should be considered only once, $(18 \times 17) / 2=153$ normalized variables (predictors) were obtained.

These predictors were used as variables for LDA models, which were constructed using SPSS software (v. 12.0.1, SPSS Inc., Chicago, IL). Linear discriminant analysis, a supervised classificatory technique, is widely recognized as an excellent tool to obtain vectors showing the maximal resolution between a set of previously defined categories. In LDA, vectors minimizing Wilks' lambda are obtained (Vandeginste et al., 1998). This parameter is calculated as the sum of squares of the distances between points belonging to the same category divided by the total sum of squares. Values of Wilks' lambda approaching zero are obtained with well-resolved categories, whereas overlapped categories made Wilks' lambda approach 1 . Up to $\mathrm{N}-1$ discriminant vectors are constructed by LDA, $\mathrm{N}$ being the lowest value for either the number of predictors or the number of categories. The selection of the predictors to be included in the LDA models was performed using the SPSS stepwise algorithm. According to this algorithm, a predictor is selected when the reduction of Wilks' lambda produced after its inclusion in the model exceeds the entrance threshold of a test of comparison of variances or $F$-test $\left(\mathrm{F}_{\text {in }}\right)$. However, the entrance of a new predictor modifies the significance of those predictors that are already present in the model. For this reason, after the inclusion of a new predictor, a rejection threshold $\left(\mathrm{F}_{\text {out }}\right)$ is used to decide whether one of the other predictors should be removed from the model. The process terminates when there are no predictors entering or being eliminated from the model. The default probability values of $\mathrm{F}_{\text {in }}$ and $\mathrm{F}_{\text {out }}, 0.05$ and 0.10 , respectively, were adopted.

\section{RESULTS AND DISCUSSION}

\section{FTIR Analysis}

Fourier transform infrared spectra of the 33 Pecorino cheeses indicated in Table 1 were collected. The spectra of 6 samples, corresponding to 2 semi-hard non-fossa, 2 hard fossa, and 2 hard nonfossa cheeses, are shown in Figure 1. Several differences between the spectra of these cheeses were observed, especially in regions 3,700 to 3,000 and 1,700 to $1,000 \mathrm{~cm}^{-1}$. However, differences in these regions were observed for cheeses corresponding 


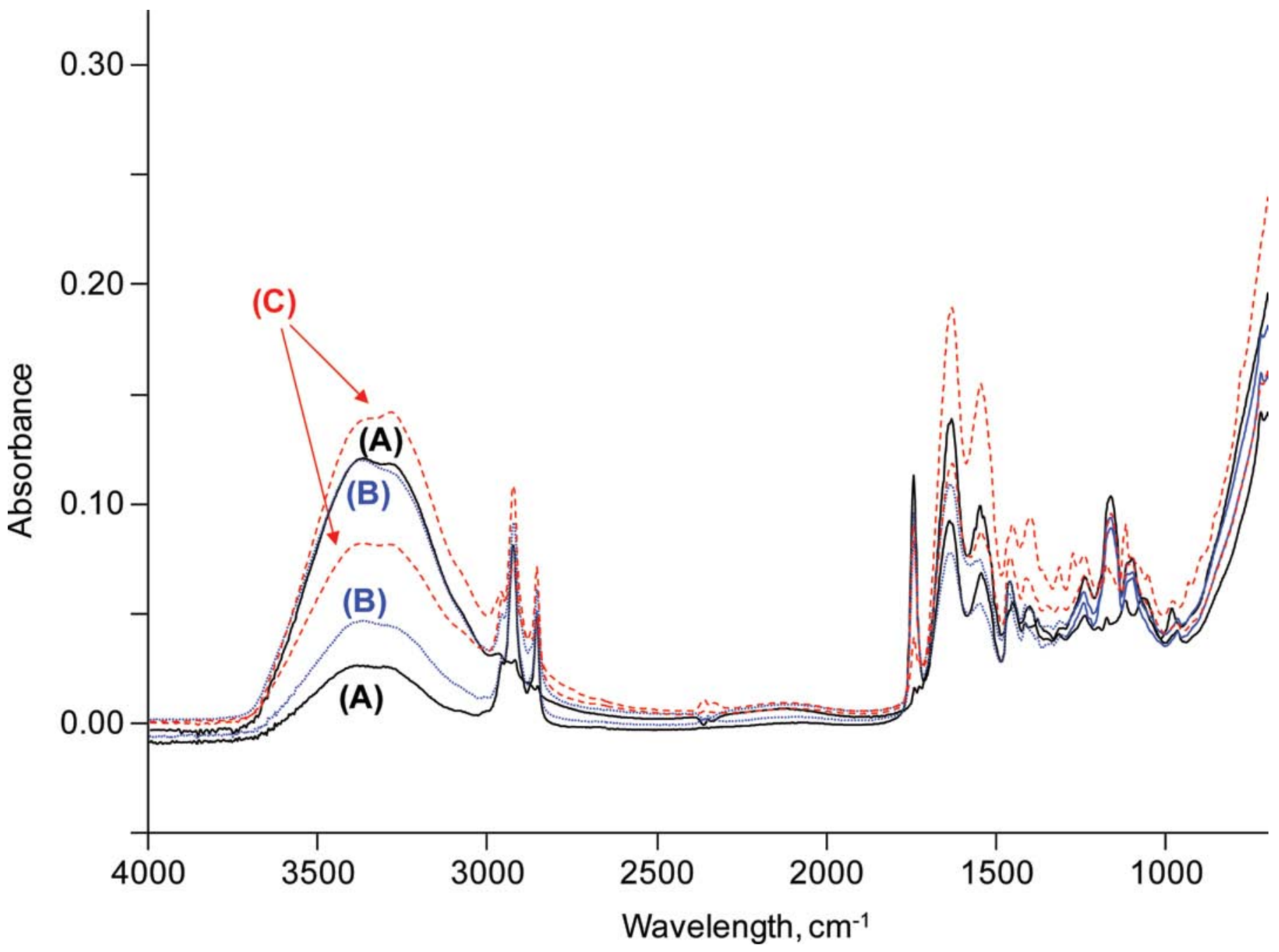

Figure 1. Fourier transform infrared spectra of Pecorino cheese samples of semi-hard (A, solid lines), hard fossa (B, dotted lines), and hard nonfossa $(\mathrm{C}$, dashed lines). Color version available in the online PDF.

to a same category. Then, to enhance all the differences that were not appreciated straight away in the spectra of the cheeses, the peak areas of the 18 selected regions were conveniently handled by multivariate statistical techniques.

\section{Classification of Pecorino Cheeses According to Their Ripening Times}

A first LDA model was constructed to classify the samples according to their ripening time (semi-hard and hard). For this purpose, a matrix containing the 99 available objects (which corresponded to the mean of the 3 spectra measured for each portion) and the 153 predictors obtained after the normalization procedure was constructed. This matrix was randomly divided into 2 sets: training and evaluation. The training set com- prised 89 objects (19 semi-hard and 70 hard extracts) and the evaluation set comprised 10 objects (5 semihard and 5 hard extracts). Another column, containing the 2 categories (semi-hard and hard), was also added to these matrices. An excellent resolution between both categories was achieved with a Wilks' lambda of 0.055 . The variables selected by the SPSS stepwise algorithm and the corresponding standardized coefficients of the model are given in Table 3. According to this table, the main infrared (IR) regions selected by the algorithm to construct the LDA model corresponded to $-\mathrm{N}-\mathrm{H}$ (stretching and bending), -O-H (stretching), -C-O (stretching), - $\mathrm{C}-\mathrm{H}\left(\mathrm{CH}_{2}\right.$ and $\mathrm{CH}_{3}$, bending), $-\mathrm{C}=\mathrm{O}$ (ester, stretching), and -C-O (stretching). A plot representing the discriminant function against the category was shown in Figure 2. When a leave-one-out validation method was applied to the training set, all the points 


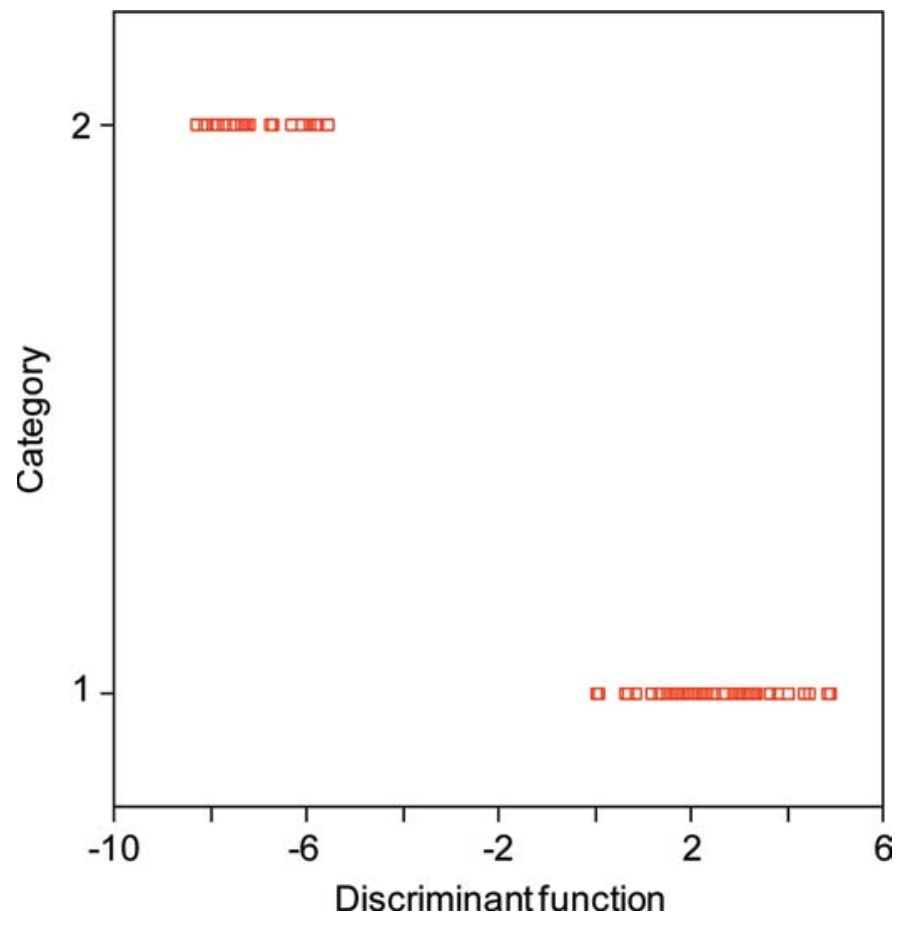

Figure 2. Score plot on the plane of the discriminant function versus the category ( $1=$ semi-hard; $2=$ hard $)$ of the linear discriminant analysis model constructed to classify Pecorino cheeses according to their ripening time. Color version available in the online PDF.

were correctly classified. Concerning the evaluation set, all the objects were correctly assigned with an assignment probability higher than $95 \%$.

\section{Classification of Pecorino Cheeses According to Their Manufacturing Technique}

Another LDA model was constructed to classify the cheese samples according to their manufacturing technique. In this case, the training set comprised 89 objects (28 fossa and 61 nonfossa) and the evaluation set comprised 10 objects (5 fossa, 5 nonfossa). Also in this case, an excellent resolution between both categories was achieved with a Wilks' lambda of 0.075 . The variables selected by the SPSS stepwise algorithm and the corresponding standardized coefficients of the model are given in Table 4. According to this table, the main IR regions selected by the algorithm to construct the LDA model corresponded to $-\mathrm{N}-\mathrm{H}$ (stretching and bending), - $\mathrm{O}-\mathrm{H}$ (stretching and bending in plane), -C-O (stretching), and $-\mathrm{CH}_{2^{-}}$(bending). A plot representing the discriminant function against the category is shown in Figure 3. When a leave-one-out validation method was applied to the training set, all the points were correctly classified. Concerning the evaluation set, all the objects were correctly assigned with an assignment probability higher than $95 \%$.
Table 3. Predictors selected and corresponding standardized coefficients of the first discriminant function $(f 1)$ of the linear discriminant analysis model constructed to classify Pecorino cheeses according to their ripening time

\begin{tabular}{lr}
\hline Predictor $^{1}$ & \multicolumn{1}{c}{$f_{1}$} \\
\hline $1 / 2$ & 3.43 \\
$1 / 8$ & -19.62 \\
$1 / 10$ & 13.56 \\
$1 / 17$ & -19.54 \\
$2 / 9$ & 19.85 \\
$4 / 5$ & -4.77 \\
$6 / 12$ & 23.86 \\
$6 / 17$ & -10.74 \\
$7 / 13$ & 4.99 \\
$8 / 14$ & 17.66 \\
$8 / 18$ & 6.36 \\
$14 / 16$ & -3.10 \\
$15 / 16$ & 19.44 \\
\hline
\end{tabular}

${ }^{1}$ Ratios of wavelength regions (Table 2) obtained according to the normalization procedure.

\section{Classification of Pecorino Cheeses According to both Ripening Time and Manufacturing Technique}

Finally, a third LDA model was constructed to classify samples according to both ripening time and manufacturing technique. The training matrix comprised 87 objects (20 semi-hard, 29 hard fossa, and 38 hard nonfossa), and the evaluation set comprised 12 objects (4 semi-hard, 4 hard fossa, and 4 hard nonfossa). With this model, a good resolution between the 3 categories was achieved (Wilks' lambda $=0.212$ ). The variables selected by the SPSS stepwise algorithm and the corresponding standardized coefficients of the model showing the predictors with large discriminant capabilities are given in Table 5. According to this table, the main

Table 4. Predictors selected and corresponding standardized coefficients of the first discriminant function $(f 1)$ of the linear discriminant analysis model constructed to classify Pecorino cheeses according to their manufacturing technique

\begin{tabular}{lr}
\hline Predictor $^{1}$ & $f_{1}$ \\
\hline $1 / 7$ & -12.79 \\
$2 / 8$ & 24.37 \\
$3 / 8$ & -12.05 \\
$3 / 18$ & 4.57 \\
$4 / 13$ & -14.80 \\
$5 / 7$ & -3.64 \\
$5 / 12$ & 15.54 \\
$5 / 13$ & 16.31 \\
$5 / 14$ & -19.36 \\
$7 / 8$ & 9.72 \\
$7 / 10$ & -16.17 \\
$8 / 11$ & 20.40 \\
$11 / 14$ & 8.20 \\
$12 / 16$ & -9.58 \\
$15 / 16$ & 20.04 \\
\hline
\end{tabular}

${ }^{1}$ Ratios of wavelength regions (Table 2) obtained according to the normalization procedure. 
Table 5. Predictors selected and corresponding standardized coefficients of the first and second discriminant functions ( $f 1$ and $f 2)$ of the linear discriminant analysis model constructed to classify Pecorino cheeses according to their ripening time and manufacturing technique

\begin{tabular}{lrc}
\hline Predictor $^{1}$ & $f_{1}$ & $f_{2}$ \\
\hline $1 / 2$ & 1.45 & -2.26 \\
$1 / 6$ & 1.04 & 2.33 \\
$1 / 17$ & -12.67 & 11.64 \\
$2 / 3$ & -2.46 & 0.001 \\
$2 / 15$ & -2.96 & -11.32 \\
$2 / 17$ & 21.68 & 2.86 \\
$3 / 14$ & -10.78 & -9.28 \\
$5 / 7$ & -14.48 & -4.93 \\
$5 / 9$ & 15.70 & 7.07 \\
$6 / 11$ & -11.14 & 17.66 \\
$6 / 12$ & 16.29 & -12.87 \\
$7 / 17$ & -9.08 & -4.46 \\
$8 / 15$ & 15.54 & 2.45 \\
$10 / 11$ & 3.56 & 2.56 \\
$10 / 13$ & 7.48 & 9.45 \\
$10 / 14$ & 0.04 & -4.71 \\
$11 / 15$ & -11.15 & 0.14 \\
$13 / 17$ & 2.12 & 1.07 \\
$15 / 16$ & 4.94 & -5.51 \\
\hline
\end{tabular}

${ }^{1}$ Ratios of wavelength regions (Table 2) obtained according to the normalization procedure.

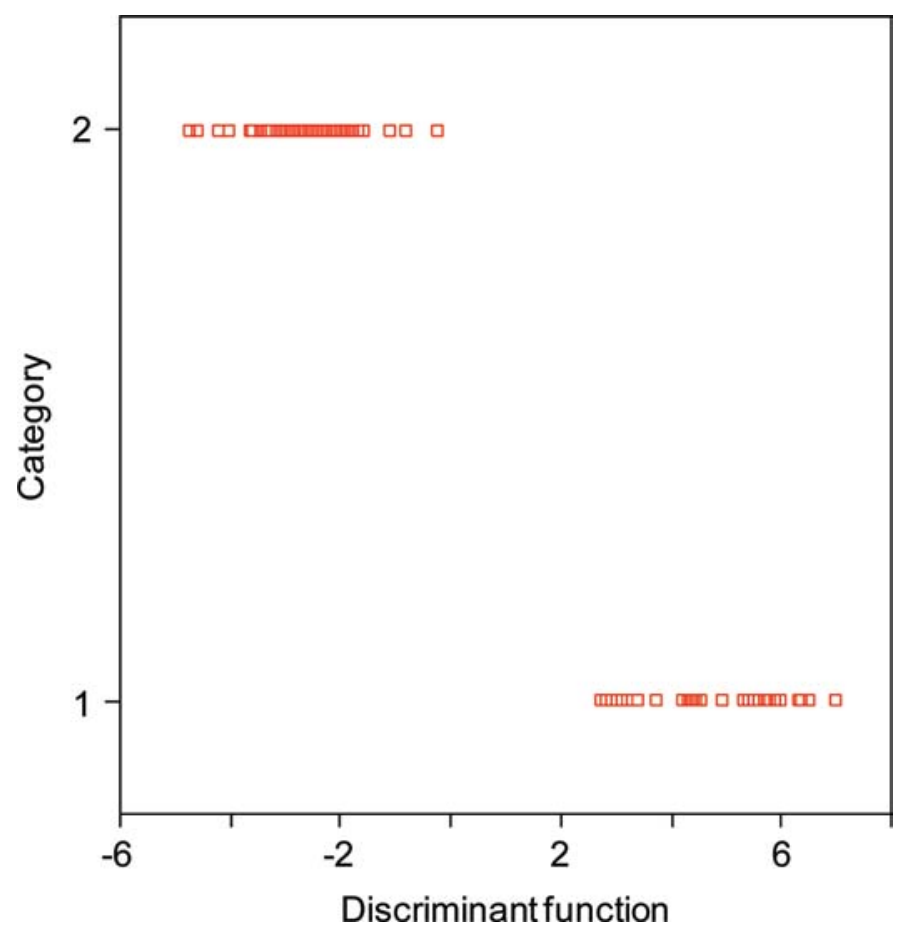

Figure 3. Score plot on the plane of the discriminant function versus the category ( $1=$ fossa; $2=$ nonfossa $)$ of the linear discriminant analysis model constructed to classify Pecorino cheeses according to their manufacturing technique. Color version available in the online PDF.

\section{+ Semi-hard \\ - Hard "fossa" \\ 口 Hard "non-fossa"}

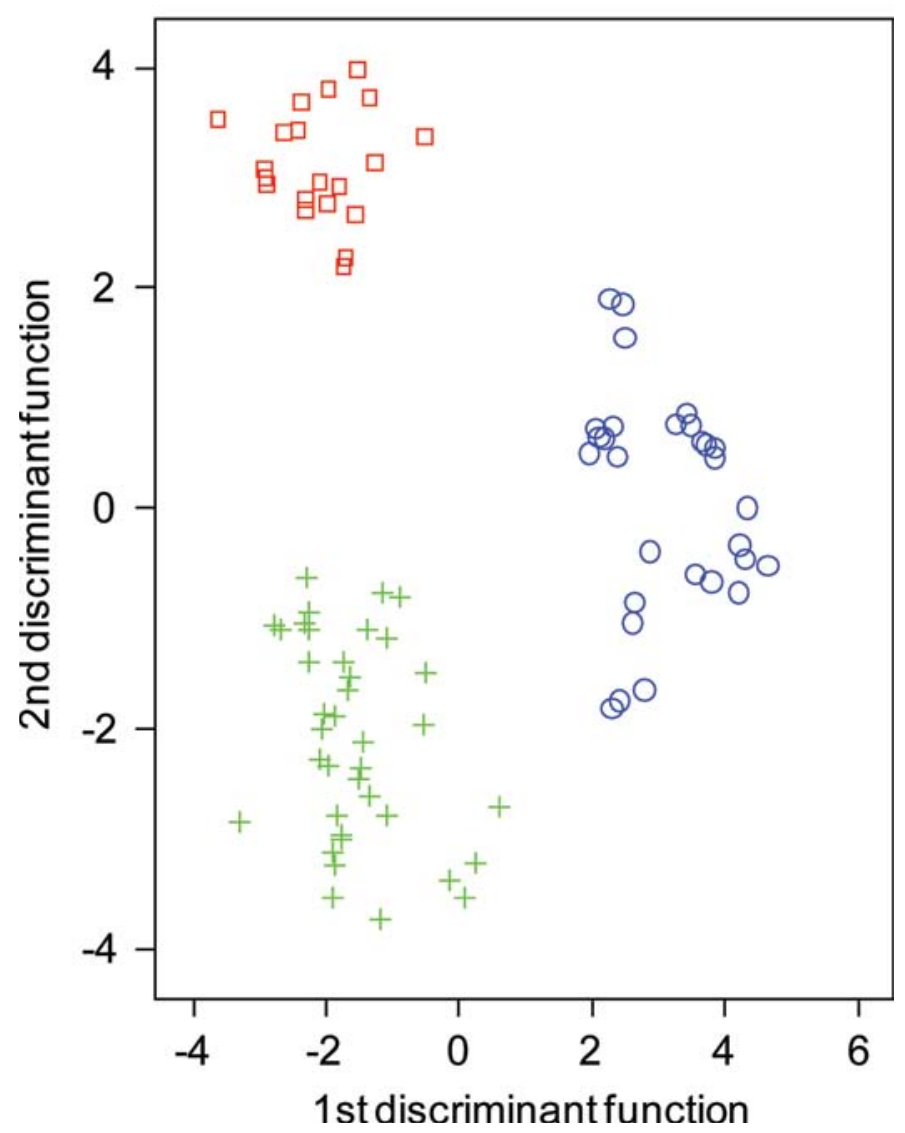

Figure 4. Score plot on the plane of the first and second discriminant functions of the linear discriminant analysis model constructed to classify Pecorino cheeses according to their ripening time and manufacturing technique. Color version available in the online PDF.

IR regions selected by the algorithm to construct the LDA model corresponded to $-\mathrm{N}-\mathrm{H}$ (stretching), $-\mathrm{O}-\mathrm{H}$ (stretching and bending), -C-O (stretching), and -C $=\mathrm{O}$ (ester, stretching). Figure 4 shows a score plot on the plane of the 2 discriminant functions obtained. When a leave-one-out validation method was applied to the training set, all the points were correctly classified. Concerning the evaluation set, all the objects were correctly assigned with an assignment probability higher than $95 \%$. Thus, the possibility of classifying Pecorino cheeses according to their ripening time, manufacturing technique, or both by using FTIR data has been demonstrated.

\section{REFERENCES}

Blazquez, C., G. Downey, D. O'Callaghan, V. Howard, C. Delahunty, and E. Sheehan. 2006. Modelling of sensory and instrumental tex- 
ture parameters in processed cheese by near infrared reflectance spectroscopy. J. Dairy Res. 73:58-69.

Chen, M., J. Irudayaraj, and D. J. McMahon. 1998. Examination of full fat and reduced fat Cheddar cheese during ripening by Fourier transform infrared spectroscopy. J. Dairy Sci. 81:2791-2797.

Coates, J. 2000. Interpretation of infrared spectra, a practical approach. Pages 10815-10837 in Encyclopedia of Analytical Chemistry. R. A. Meyers, ed. John Wiley \& Sons, Chichester, UK.

Contarini, G., M. Povolo, P. M. Toppino, B. Radovic, M. Lipp, and E. Anklam. 2001. Comparison of three different techniques for the discrimination of cheese: Application to the ewe's cheese. Milchwissenschaft 56:136-140.

Downey, G., E. Sheehan, C. Delahunty, D. O'Callaghan, T. Guinee, and V. Howard. 2005. Prediction of maturity and sensory attributes of Cheddar cheese using near-infrared spectroscopy. Int. Dairy J. 15:701-709.

Fallico, V., P. L. H. McSweeney, K. J. Siebert, J. Horne, S. Carpino, and G. Licitra. 2004. Chemometric analysis of proteolysis during ripening of Ragusano cheese. J. Dairy Sci. 87:3138-3152.

Fox, P. F., J. Low, P. L. H. McSweeney, and J. M. Wallace. 1993. Biochemistry of cheese ripening. Pages 389-438 in Cheese: Chemistry, Physics, and Microbiology. 2nd ed. P. F. Fox, ed. Chapman \& Hall, London, UK.

Gagnaire, V., D. Mollé, M. Herrouin, and J. Leonil. 2001. Peptides identified during Emmental cheese ripening: Origin and proteolytic systems involved. J. Agric. Food Chem. 49:4402-4413.

Gorostiza, A., A. J. Cichoscki, A. T. Valduga, E. Valduga, A. Bernardo, and J. M. Fresno. 2004. Changes in soluble nitrogenous compounds, caseins and free amino acids during ripening of artisanal Prato cheese; a Brazilian semi-hard cows variety. Food Chem. 85:407-414.

Karoui, R., E. Dufour, L. Pillonel, D. Picque, T. Cattenoz, and J. O. Bosset. 2004. Fluorescence and infrared spectroscopies: A tool for the determination of the geographic origin of Emmental cheeses manufactured during summer. Lait 84:359-374.

Karoui, R., E. Dufour, L. Pillonel, E. Schaller, D. Picque, and T. Cattenoz. 2005. The potential of combined infrared and fluorescence spectroscopies as a method of determination of the geographic origin of Emmental cheeses. Int. Dairy J. 15:287-298.
Lerma-García, M. J., G. Ramis-Ramos, J. M. Herrero-Martínez, and E. F. Simó-Alfonso. 2010. Authentication of extra virgin olive oils by Fourier-transform infrared spectroscopy. Food Chem. 118:7883.

Luykx, D. M. A. M., and S. M. van Ruth. 2008. A review of analytical methods for determining the geographical origin of food products. Food Chem. 107:897-911.

Martin-del-Campo, S. T., D. Picque, R. Cosio-Ramirez, and G. Corrieu. 2007. Middle infrared spectroscopy characterization of ripening stages of Camembert type cheeses. Int. Dairy J. 17:835-845.

Mazerolles, G., M. F. Devaux, G. Duboz, M. H. Duployer, N. M. Riou, and E. Dufour. 2001. Infrared and fluorescence spectroscopy for monitoring protein structure and interaction changes during cheese ripening. Lait 81:509-527.

McSweeney, P. L. H., and M. J. Sousa. 2000. Biochemical pathways for the production of flavor compounds in cheese during ripening: A review. Lait 80:293-324.

Moatsou, G., T. Massouras, I. Kandarakis, and E. Anifantakis. 2002 Evolution of proteolysis during the ripening of traditional Feta cheese. Lait 82:601-611.

Poveda, J. M., A. Garcia, P. J. Martin-Alvarez, and L. Cabezas. 2004 Application of partial least squares (PLS) regression to predict the ripening time of Manchego cheese. Food Chem. 84:29-33.

Rodriguez-Saona, L. E., N. Koca, W. J. Harper, and V. B. Alvarez. 2006. Rapid determination of Swiss cheese composition by Fourier transform infrared/attenuated total reflectance spectroscopy. J. Dairy Sci. 89:1407-1412.

Silverstein, R. M., G. C. Bassler, and T. C. Morrill. 1981. Spectrometric Identification of Organic Compounds. John Wiley \& Sons, Chichester, UK.

Vandeginste, B. G. M., D. L. Massart, L. M. C. Buydens, S. De Jong, P. J. Lewi, and J. Smeyers-Verbeke. 1998. Data handling in science and technology: Part B. Pages 237-238 in Handbook of Chemometrics and Qualimetrics. Elsevier Science B.V, Amsterdam, the Netherlands.

Verdini, R. A., S. E. Zorrilla, and A. C. Rubiolo. 2004. Characterisation of soft cheese proteolysis by RP-HPLC analysis of its nitrogenous fractions. Effect of ripening time and sampling zone. Int. Dairy J. 14:445-454. 